Review Article

\title{
Generalized review of the successes \& challenges of medicine; an insight of the past, present and future prospects
} \author{
Syed A. Aziz', Shamoon Noushad ${ }^{2}$ \& Sadaf Ahmed ${ }^{2 \& 3}$ \\ ${ }^{1}$ Regulatory Toxicology Research Division, Health Canada and Department of Pathology University of Ottawa, Canada. \\ ${ }^{2}$ Advanced Educational Institute and Research Center, Pakistan.
}

${ }^{3}$ University of Karachi, Physiology

\begin{abstract}
Evidence from recent millennia demonstrates the progressive efforts of humans to prevent diagnose and cure diseases. Understanding diseases and developing cures has always been a challenge for various reasons, but the successes surpass the setbacks in terms of discoveries. Overcoming infectious diseases has shown the most successes as well as challenges, and still the case may be so. New technologies are bringing many opportunities for the future. While cures for cancer, heart disease, diabetes, AIDS, etc. still remain to be included in the successes, on the other hand regenerative medicine, nanotechnologies and point of care are very promising developments. In this review we have tried to cover the past, present and future expectation and challenges associated with medicine and surgery.
\end{abstract}

\section{KEYWORDS}

Medical History, Galvanometer, Point of Care Testing, Nanotechnology

\section{INTRODUCTION}

The challenge of finding cures for diseases must have been on the agenda of humans since men became self-aware, and learned to care for themselves and others. The gift of curiosity has made humans far more successful in every walk of life than their fellow creatures. Multifariousness of natural resources has served not only for basic human needs but also for health care. Since time immemorial with the oldest civilization, development was supported by the biodiversity in flora and fauna that traditional systems of medicines used for preventing or treating illness. In this review our main focus is on the major discoveries in medicine. The invention of medicine is discussed from $2600 \mathrm{BC}$ forward, along with discussion of how the concept of medicine changed through necessity and the passage of time.

\section{MEDICAL PAST ERA}

\section{- $2600 \mathrm{BC}$ to $1 \mathrm{BC}$}

Prehistoric man had knowledge of medical procedures; documented evidence of procedures was only possible after the invention of writing. Some of the first recorded evidence comes from the ancient Egyptians, whose health professionals had discovered different pathological conditions of the human body, describe about 200 diseases with diagnosis and treatment., also used a large range of drugs obtained from herbs and minerals. Egyptian physicians also used ointments for wounds and treated chest complaints by getting the patient to inhale steam as it was believed that the human body was full of passages that acted like irrigation canals and these canals were sometimes blocked, which caused the illness. Laxatives has been used to induce vomiting (Peltier, 1993). Of course, this has been known of their knowledge of human anatomy through their mummification practices. For instance, to remove the brain, Egyptian physician knew how to break thin bone between brain and sinus, and then extracting it by inserting long hooked implement through nostrils. Egyptian physician also had a general knowledge of the location in the body cavity of the inner organs, which detached through a small cut in the left groin. How this knowledge was passed on to the practitioners of medicine is unknown. Egyptian physician were also at least somewhat aware of the importance of diet in both balance and moderation (Konomi, 2002). While they also knew about some common diseases such as colds, asthma, headaches, and stomach aches and may have treated them with herbal remediation, other diseases were probably treated by some means of their understanding. Wounds from war-like lacerations were treated with surgery. Egyptian physician used herbs which included opium, coca, ephedrine, sagrada, digitalis, caffeine, carcara, chaulmoogra, cinchona, ipacacuanha, podophyllum, pyrethrum, squill, strammonium and belladonna (Withington, 1894). A number of plants used in wound treatment, like hypericum, have been shown to have antibacterial properties. Due to a soothing and cooling effect, some plants, especially leaves or grasses, were also used as bandages (Forrest, 1982). Garlic was used for not only for antibacterial properties but also for antiviral, antifungal and antiprotozoal purposes. Garlic was used for strengthening cardiovascular and immune system (Harris, 2001). Honey had been valued for centuries: it was used for treating wounds and infections (Zumla, 1989).

\section{Documentations}

Documentation of this historical era starts with the earliest known medical text knows as Medical Papyri (Figure 2). It is a thick paper-like material produced from the pith of the papyrus plant. Papyrus was first manufactured in Egypt and Southern Sudan. Ancient Egyptians used this paper to described gynecological symptoms and anatomy of reproductive organ. Egyptian physician had a test for pregnancy and different method for diagnosing the sex of fetus (Mostafa, 2004) while another Papyrus gathered information that explained 872 treatments recipes for different diseases and more than 400 drugs were described these discoveries were very helpful for further progress in Egypt. Before the proper recipe of drugs, for thousands of years, the ancient Egyptians and Greeks only used medicinal plants as cures without any proportion. As history move forward there is another papyrus containing 18 pages of medical prescription concentrating on treatments that deals with problems of blood, hair, urinary system, and bites (Hickey,2003) these were used for providing evidences for remedial methods for different problems like headaches and digestive problems (Marry, 2004). Some of test also includes sections on incantations and magic spells that would be applied on patients before, during and after specific treatment (Hoeppli, 1956). The most common remedy described in the papyrus is ochre or medicinal clay that can be prescribed for various intestinal complaints like having any obstruction or any constriction and also deals with complications related to eye like blurriness, pain or any eye side complaints (Goel, 2010). Health professionals also focused on herbs that were intended to preventing diseases, such as like Saffron, which has long medicinal history for healing. Several 
recent research studies have also determined that it has possible anti-mutagenic, anti-carcinogenic and antioxidant like characteristics (Dwyer, 2011; Dante, 2011; Causey, 2012).The papyrus also describes realistic possibilities of anatomical, physiological and pathological observations; various pathological situations where brain injuries have an influence on parts of the body were recognized, such as paralysis etc. They also describe the relationship between the location of a cranial injury and the side of the body affected, while also suggesting that crushing injuries of vertebrae were noted to impair motor and sensory functions (John, 1996). However Egyptian surgery was limited to such things as treating broken bones and wounds and dealing with boils and Abscesses.
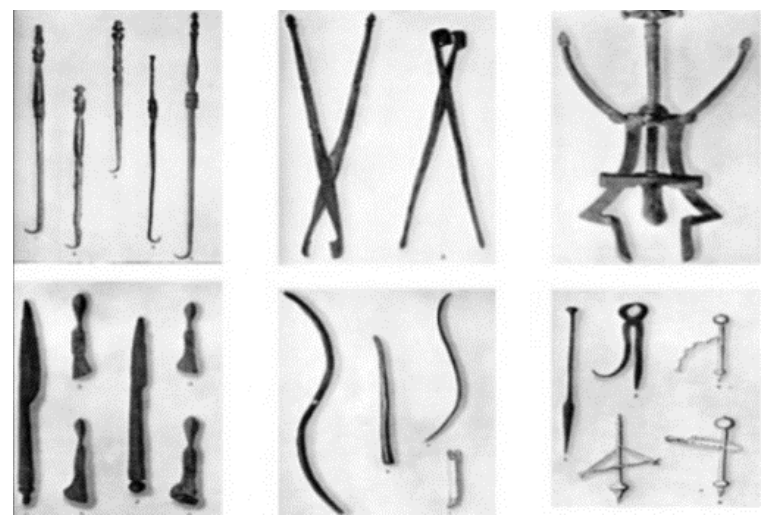

Figure 1 : Ancient surgical tools: scalpels, bronze, uvula, bone drills tool, hooks, and bone forceps.

\section{Native Americans}

Ancient papyrus texts mentioned the use of surgical tools in several of these texts offer a brief explanation of how some of the instruments were used by doctors in antiquity (Figure, 1). Scalpels and hooks made from steel or bronze or a mixture of both were used regularly by Greek and Roman doctors. Both of these types of hooks are still used by modern surgeons for many of the same purposes. For instance, forceps with Uvula crushing, finely-toothed jaws were probably designed to facilitate the amputation of the uvula. Bone drills driven in a rotary motion by means of a thong in a variety of configurations were used for surgical removal of bone fragments generated after fracture (Figure, 1). Most of these instruments, which seemed to have been available to Hippocrates, were used throughout the late Roman Empire and in recognizable forms are still being used by physicians today (Harvey,1942). Egyptian physician knew that honey helped to prevent wounds becoming infected and are a natural antiseptic, wounds were dressed with the help of willow bark, which also has antiseptic and analgesic, anti-inflammatory properties (Biegert, 2004). In another papyrus text, there is the first known description of the cranial structures, the meninges, the cerebrospinal fluid, the external surface of the brain and the intracranial pulsations (Sullivan, 1996). The word 'brain' appeared for the first time in any language (Wakounig, 2012) in Latin. This papyrus demonstrates an Egyptian level of knowledge of medicines that surpassed that of Hippocrates, who lived 1000 years later. In 1300 BC, another version of papyrus having twenty four pages deals with contraception and fertility tests for better approaches in dealing with women's health related problems. By 600 BC, Egyptian physicians had described smallpox, a very serious contagious illness, later shown to be caused by a virus called the variola (Fenner, 1976).

To Native Americans, health is a continual process of staying strong spiritually, mentally, and physically. This strength keeps away or overcomes the forces that cause illness. People must stay in harmony with themselves, other people, their natural environment, and their Creator. They believe that people should try to maintain constant, daily harmony and contact with the Creator follow all sacred teachings, and treat all life (animals, plants, rocks, rivers, rainbows, etc., along with people) with respect. Native Americans believe that violating tribal tenets or laws has consequences like physical or mental illness, disability, ongoing bad luck, or trauma. The violation must be set right before harmony and health can be restored. They believe that most illnesses are related to a spiritual cause, which creates an imbalance between the body, mind, and spirit. It is bad spirits that cause the harm (Barrett, 1933).

The body is an expression of the spirit to Native Americans. Each person is responsible for his/her own health. All thoughts and actions have consequences, creating harmony or disharmony. Disharmony can cause illness. Native American medicine includes a variety of rituals and practices; the use of herbal remedies gathered from the surrounding environment and sometimes traded over long distances; and healing by medicine people who use naturalist or personalistic healing. Rituals and practices bring participants into harmony with themselves, their tribe, and all of life. They include the use of sweat baths, usually in a "sweat lodge," to purify and heal; wearing medicine bags and charms; and the use of ancient healing rituals and ceremonies. When a medicine person helps a person heal him/herself, this is considered to be a private, doctor/patient relationship. Ceremonies are used to help groups of people return to harmony, but they are not used for individual healing (Michael, 1991).

Native Americans used herbs to purify the spirit and bring balance to people who are unhealthy in spirit, mind, or body. They learned about the healing powers of herbs by watching sick animals. Tobacco, one of the most sacred plants to Native Americans, is used in some way in nearly every cure. It is smoked pure and is not mixed with chemicals. Sage, an abundant and pretty plant with blue flowers and light white or grayish leaves, is believed to protect against bad spirits and to draw them out of the body or the soul. Native Americans use sage for many purposes: to heal problems of the stomach, colon, nasal passages, kidneys, liver, lungs, pores of the skin, bones, and sex organs; on the hair and scalp; to heal burns and grazes; as an antiseptic for allergies, colds, and fever; as a gargle for sore throat; and as a tea to calm the nerves. Cedar, a tall evergreen tree, is a milder medicine than sage. It is combined with sage and sweet grass, a plant that grows in damp environments like marshes or near water, to make a powerful concoction used in the scared smudging ceremony. Cedar fruit and leaves are boiled and then drunk for coughs. Forehead colds, cedar is burned and inhaled (Fernald, 1943).

Medicines that treated some of the oldest known diseases were used and spread by Native Americans; many had important medical uses and are still used today. In the Andes, Incas used "Peruvian bark," or quinine, to cure cramps, chills, heart-rhythm disorders, and other ailments. In the early 17 th century, quinine was used in Europe to treat malaria, marking the beginning of modern pharmacology. Indians of the Amazon cured amoebic dysentery (a deadly infection of the intestines) with a medicine they called ipecac, made from the roots of the plants Cephaelisipecacuanha and C. acuminata. Ipecac makes people vomit, thus expelling the poisons from the body. It is still used for this purpose today by poison clinics worldwide. Curare, used as a poison on arrows by Native Americans in the Amazon, is used as a muscle relaxant in modern medicine. It was the first treatment for tetanus, and was used to relax abdominal muscles before surgery and to relax patients enough to permit a breathing tube to be inserted into the windpipe during surgery. Today, curare is part of many different muscle-relaxant drugs. The most commonly used laxative worldwide came from Native Americans in northern 
California and Oregon, who used the bark of the cascarabuckthorn as a cure for constipation. In South America, Native Americans used the coca bush, which replaced ether and launched local anesthesia in medical use. Today, cocaine is used innovocaine, one of the most important anesthetics in the world (Lobelia, 2007).

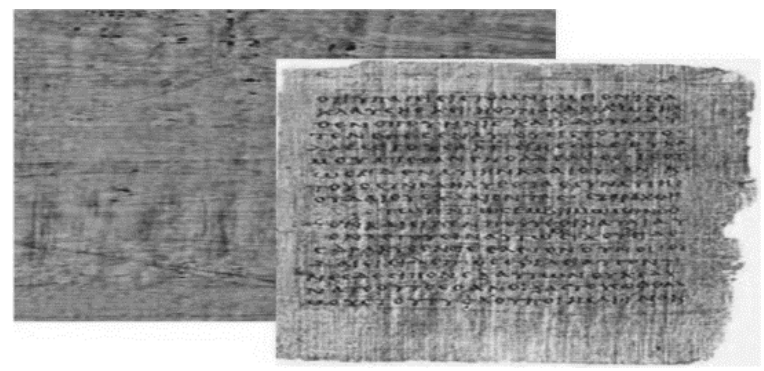

Figure 2: Ancient papyrus

\section{Hippocrates}

Hippocrates (460 BC- 370 BC), was an ancient Greek physician of the Age of Pericles (Classical Greece), and is appraised one of the most exceptional figures in the account of medicine. He is accredited to as the father of western medicine in acquisition of his continuing endowments to the field as the founder of the Hippocratic School of Medicine (Adam, 1891). This intelligent school revolutionized medicine in ancient Greece, establishing it as a mechanism asymmetric from other fields that it had commonly been affiliated with thus ascertaining medicine as a profession. Hippocrates is accredited with being the first person to accept that diseases were brought about naturally, not because of superstition and gods (Fishchenko, 1986). Hippocrates had been accredited by the apprentices of Pythagoras of affiliating philosophy and medicine. He dissociated the discipline of medicine from religion, believing and arguing that disease was not a punishment diseased by the gods but rather the product of environmental factors, diet, and living conventionalities. Indeed there is not a single mention of an astrological apoplexy in the conclusiveness of the Hippocratic Corpus (Jones, 1868). Although, Hippocrates did work with many principles that were based on what is now known to be incorrect anatomy and physiology, such as Humorism. Another considerable concept in Hippocratic medicine was that of a crisis, a point in the advancement of disease at which both the illness would originate to triumph and the patient would accept to death, or the opposite would occur and natural approaches would make the patient recover. Hippocrates and his followers were first to explain numerous diseases and medical conditions. $\mathrm{He}$ is attributed acknowledge for the first description of clubbing of the fingers, a critical diagnostic sign in chronic supportive lung disease, lung cancer and cyanotic heart disease. For this conceptualization, clubbed fingers are sometimes accredited to as "Hippocratic fingers". Hippocrates was also the first physician to describe Hippocratic face in Prognosis (Plato, 2012).

The Hippocratic School of medicine accounted well the diseases of the human rectum and the treatment thereof, despite the school's poor theory of medicine. Hemorrhoids, for example, though accepted to be driven by an excess of bile and phlegm, were treated by Hippocratic physicians in relatively advanced ways. Cautery and excision are accounted in the Hippocratic Corpus, in addition to the preferred courses: ligating the hemorrhoids and drying them with a hot iron. Other treatments such as accosting various lubricates are suggested as well. Today, "treatment [for hemorrhoids] still includes burning, strangling, and excising (Rutkow, 1993). Also, some of the fundamental concepts of proctoscopy outlined in the Corpus are still in use. For example, the uses of the rectal speculum, a common medical device, are discussed in the Hippocratic Corpus. This constructs the earliest accounted citation to endoscopy. Hippocrates often used lifestyle adaptations such as diet and exercise to treat diseases such as diabetes, what is today called lifestyle medicine. He is often quoted with "Let food be your medicine, and medicine be your food" and "Walking is man's best medicine (Singer, 1962).

\section{Indian}

The oldest known medical texts from the Indian subcontinent are the Ayurveda texts the SuśrutaSahitā and the CharakaSahitā, written in Sanskrit. Ayurveda practitioners who are commonly known as veda developed a number of medicinal preparations and surgical procedures for the treatment of various ailments (Monier, 1964). At that time, this system of traditional medicine was called the "science of the eight components". It included the cure of diseases affecting the body, separate treatments for children that differed from the treatments given to adults, removal of any substance which has entered the body by cutting off tissue, a drug that that can make render people "dead" for three days for certain purposes, and cures of diseases of the eyes or ears by puncturing them with sharp instruments. The treatment of mental diseases was based on the conception that are due to demoniacal or other possessed influences. Ayurveda practitioners prescribed treatments for reducing inflammation (Sobkowiak, 2009). Later there developed a theory of medicine establishing connections between brain and sensory organs that outlines or focuses on paths of optic nerves. Vede also considered the brain as the main organ related to the mind. Then as vede slowly became aware of diseases and pathologies, diseases were understood as disharmony or imbalance in functions or interactions between human body and its surrounding environment. Following these observations vede developed a therapy which focused and identified "patterns of disharmony".

\section{Chinese}

These "patterns of disharmony" are also the most important step in Traditional Chinese medical diagnosis which depended on tongue and pulse conditions. A traditional Chinese medical practitioner might diagnose bleeding from the mouth and nose as due to liver fire rushing upwards and heating the lung, injuring the blood vessels and giving rise to un-stanch able pouring of blood from the mouth and nose (Deadman, 1994).

\section{- $\quad 375-295 \mathrm{BC}$}

In this era physician discovered that in human body there is something which senses pain, which they named nerves. Physician further discovered that these nerves makes continuous channels of sensations and are the basis of pathologies of diseases. Physician also believed that the body was made up of four humors or liquids like phlegm, blood, yellow bile and black bile physician believed that if a person had too much of one humor they fell ill. Furthermore if a person had a fever he must have too much blood (Krieg, 1995). The word anatomy was used for the first time, and it was believed that the liver is the organ from which arteries arise, but then it was changed to the belief that arteries and veins both arises from the heart (Greenhill, 1843)and that heart have tricuspid valves that prevents the backflow (Georges-Berthier, 1914). Digestive system and pathway of food that consumed and the pathway from mouth to lungs were also discovered in this era (Gunderson, 2009). Dura-mater and cerebellum were also discovered as a part of brain and nerves are originating from Duramater of brain that helps motion and pain feelings. Catheters of Sshaped that are used in surgeries and the concept of acute and chronic disease were also developed in this era (Wellmann, 1888; Rufus, 1869). 


\section{1st century AD to 1700's AD}

The 1st century $\mathrm{AD}$, scientists discovered and modified the last invention in the field of medicine wherein neurologists discovered that there are recurrent nerves that arises from the brain and there are separate nerves for sensation and motion. It was also discovered that the basis of life is the heart, and that left ventricle is smaller and thicker than the right one (Nutton, 1973). Medicine that focuses on philosophy was examined and dietary factors and hygiene were principally concerned. Several treatments for traumatic conditions resulting in fractures and wounds were studied (Paraskevas, 2012; Walters, 1998). These studies were related to medicines that relates to chronic and acute conditions deals with inner body pathologies (Cosman, 2008).

\section{- $1000 \mathrm{AD}$}

The bleeding disorder Hemophilia was discovered with its nature as a hereditary disease. Surgical articulation of the temporal artery was used as a treatment for migraine, and many other surgical devices were discovered that helped surgeons to perform their work more effectively.

\section{- $1242 \mathrm{AD}$}

Theorists suggest that the right and left ventricles of the heart are separate and they discovered the pulmonary circulation and coronary circulation.

\section{- $1248 \mathrm{AD}$}

Natural philosophers wrote on botany and pharmacy (Loudon, 2007).Between 1280-1285scholarsdeveloped a concave lens spectacle to treat myopia - a condition of the eye where the light that comes in does not directly focus on the retina but in front of it. This causes the image that one sees when looking at a far object to be out of focus, but in focus when looking at a close object (Vincent, 2007) Since the mid-14th century in Europe the church permitted some dissections of human cadavers at medical schools. Galen's ideas continued to lead surgery and medicine. He was interested in human anatomy. However, regrettably by his time dissecting human bodies was unauthorized and he had to dissect animal bodies including apes. Although human bodies are dissimilar to animal bodies, a number of Galen's ideas were relatively wrong. In the 16th century surgery did become a little more advanced. Other surgeons dissected human bodies and realized that several of Galen's ideas were wrong. In 1543 a book published which contained accurate diagrams of a human body named The Fabric of the Human Body written by Andreas Vesalius (Siraisi 1991).

\section{- 1500sAD}

Artificial eye are known to have been made but the first known artificial eye for living patient was not used until late 6thcentury by the Romans. Artificial eye was created by using piece of flesh color cloth with an attached piece of clay that is approximately the size human eye and then securely fixed in the empty eye socket (Kelley, 1970).

In the late 1500 's $\mathrm{AD}$, natural philosophers noticed that with the change of temperature, the body shivers and the pulse accelerated. This concept awoke the need of a diagnostic device that measures body temperature so the thermometer was designed. The first clear diagram of a thermos cope was published in 1617 by Giuseppe Biancani. The first showing a scale and constituting a thermometer was developed by Robert Fludd in 1638. This was a vertical tube, closed by a bulb of air at the top, with the lower end opening into a vessel of water. The water level in the tube is controlled by the expansion and contraction of the air, so it is what would now be called an air thermometer.

During the final years of the 16th century the first microscope was developed in England by Robert Hooke. The earliest simple microscope was simply a tube with a plate for the object at one end and a lens at the opposite end that gave ten times more magnification than the real size it is also believed that the microscope was discovered by accidentally inverting a telescope (Pearce, 2002; Duffin, J.2012).

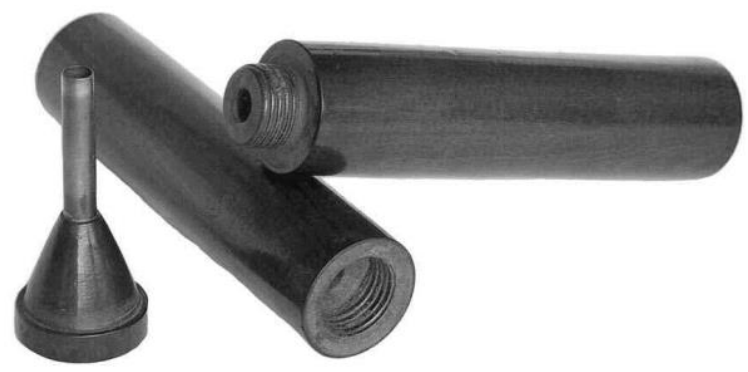

Figure 3: wooden ancient Stethoscope

\section{- 1700's A.D}

In $1747 \mathrm{AD}$, Scottish naval surgeon James Lind discovered that citrus fruits prevent scurvy. However he published his Treatise of the Scurvy in 1754, recognizing the cure for this common and dangerous disease of sailors. It took another 40 years before an official Admiralty order dictated the supply of lemon juice to ships. However, lemon juice was ineffective, as vitamin $\mathrm{C}$ is oxidized. Fresh fruit is required and the British navy did not adopt this until the Napoleonic wars.

\section{- 1796 AD}

Edward Jenner was an English physician and scientist, who was the pioneer of smallpox vaccine, the world's first vaccine in 1796 AD. He is often called "the father of immunology", and his work is said to have "saved more lives than the work of any other human (Fenner 1976)". Once the deadly disease the small pox was eradicated globally in 1979 (Tognotti 2010).

\section{- 1800's AD to 1900's AD}

In 1879 , an important discovery in the research of vaccination occurred, concerning a disease called chicken cholera, by Louis Pasteur. (Today the bacteria that cause the disease are classified in the genus Pasteurella). Pasteur continued by developing his famous vaccine for rabies. Ttetanus-1924, diphtheria -"In 1890, ShibasaburoKitasato and Emil von Behring immunized guinea pigs with heat-treated diphtheria toxin. Over the Christmas holiday in 1891 in Berlin, the first attempt to cure a person of diphtheria was made. Von Behring won the first Nobel Prize in medicine in 1901 for his work on diphtheria. Work in this field continued into the1900s.Scientists discovered vaccines for Pertussis, Tuberculosis, Tetanus, yellow Fever, polio, Measles, Rubella Vaccine and for Mumps. In 1981 the FDA approved a more sophisticated plasma-derived hepatitis B vaccine for human use. In 1992 inactivated hepatitis A vaccines were first licensed for use (Andre, F., 2002). In the early 1800's physician invent the stethoscope, and with this invention doctors diagnosed various chest conditions (Middleton, 1998).

\section{- 1883 and $1897 \mathrm{AD}$}

The late 1800 's was the era of germs and sterility and understanding the microorganisms in this period physician postulated the Germ theory, which states that various diseases are caused by the presence and actions of specific micro-organisms within the body. Louis Pasteur had some antecedents but his germ theory and its acceptance by the French Academy of Sciences in 1854 are the accepted emergence of the theory. Joseph Lister was a British surgeon and a pioneer of antiseptic surgery. By applying Louis Pasture's advances in microbiology he promoted the idea of sterile surgery while working at the Glasgow Royal Infirmary. 
Lister successfully introduced carbolic acid (now known as phenol) to sterilize surgical instruments and to clean wounds, which led to a reduction in post-operative infections and made surgery safer for patients. Natural Philosophers reported that fermentation and putrefaction are caused by organisms in the air and in the 1860s scientist reformed surgical practice by utilizing carbolic acid to exclude atmospheric germs and thus prevent putrefaction in compound fractures of bones (Richmond, 1954).

\section{AD}

Surgical advances were made in this era. Although the Greek physician Galen (AD 130-200) AD had documented the removal of corneal scars by superficial keratectomy, it was not until 1837 that the first successful transplantation of a cornea was recorded by an Irish physician, Bigger (Bigger 1837). He had been held captive by some Bedouins in the Sahara, during which time he managed to restore the sight of a pet gazelle with a homograft from another animal. It was inevitable perhaps that the earliest corneal transplants attempted in humans were xenografts. Transient success was claimed by Kissam in the U.S., who performed a graft with porcine tissue in 1838. Further experimental work in Germany by von Hippel included a partially successful lamellar xenograft using a full thickness rabbit cornea into a lamellar bed. He developed a clockwork trephine instrument with which to cut both donor and recipient cornea (Von, 1888). The first successful full-thickness corneal allograft was performed in 1905 by a surgeon named Zirm working near Prague, who restored the sight of a 45-year-old man with bilateral corneal scarring from lime burns (Zirm 1906). This early success spurred further experimentation, but it would not be for another 50 years that corneal transplantation became a reproducible procedure.

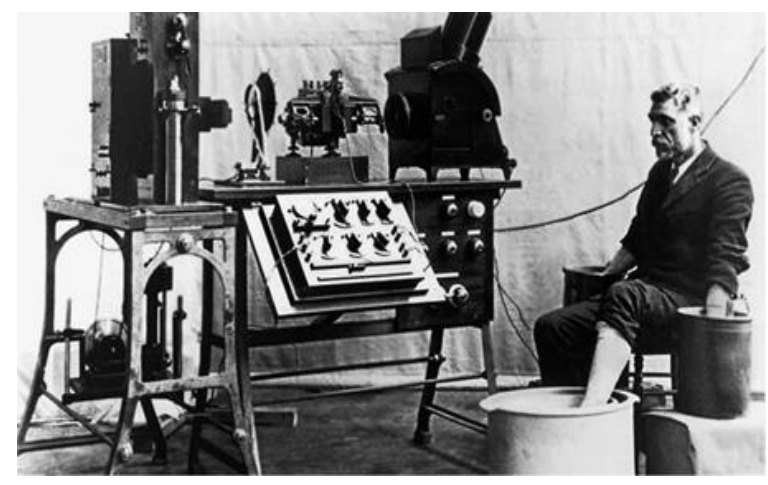

Figure 4: String galvanometer; showing the big machine with the patient rinsing his extremities in the cylindrical electrodes filled with electrolyte solution.

\section{- $\quad 1818$ AD}

British obstetrician and physiologist James Blundell performed the first successful transfusion of human blood in $1818 \mathrm{AD}$ (Ellis, 2007). In 1901 Viennese pathologist Karl Landsteiner discovered the first three blood groups. He proposed the existence of antigensin blood corpuscles, which were called $\mathrm{A}$ and $\mathrm{B}$, and agglutinins (antibodies), which were called anti-A and anti-B in blood serum. The first three blood types were named A, B, and C later renamed type $\mathrm{O}$. The $\mathrm{ABO}$-system of blood group reorganization is still called Landsteiner's classification, and soon a fourth blood type which name as type AB was introduced (Storry, 2009).

\section{- $\quad 1845 \mathrm{AD}$}

Surgeons and pharmacists introduced inhaled diethyl ether and sulphuric ether as anesthetics, which paved the way for painless surgery. General anesthetic was also developed in this era $(\sim 1845$ AD Horace Wells dentist nitrous oxide 1846 William T. G. Morton ether- U.S.A.). For the relief of headache and muscle and joint aches Aspirin or acetylsalicylic acid, which is a derivative of salicylic acid, a mild, nonnarcotic analgesic, was discovered in the same era (Bayer, 1897 early pharmaceutical research by a Germany company)

\section{- $1850 \mathrm{AD}$}

Disease diagnostics also advanced. In $1850 \mathrm{AD}$, physicians developed a very simple reagent 'strip'of sheep's wool containing stannous chloride,on which drops of urine were added to strips of sheep's wool containing stannous chloride, which gave a black product if sugar was present, it was indicated by a black product on the strip.Reagent strips today have not changed in appearance, but now only require $0.3-1 \mu \mathrm{L}$ blood, and electrode biosensor strips dominate the market.While there are slight variations, the modern blood glucose meter has evolved into an almost standard size and shape. Theyare battery powered, handheld, easy to use, and contain advanced microelectronics and software to perform a range of useful functions (Emanuel, 2003)

\section{- $\quad 1853 \mathrm{AD}$}

Salicylates have a long history of use. Hippocrates, Galen, and medieval herbalist relied on salicylate containing the botanicals for their palliative properties. The medicinal properties of will bark (Salix albavulgaris) have been appreciated by native people for centuries. In the mid-19th century, the active ingredient of willow bark, salicylic acid was isolated and shortly thereafter was synthesize from phenol. It gained widespread use in extemporaneously compounded as a pain reliever, antiinflammatory, and antipyretic. In the letter portion of the 19th century, the Bayer Company in Germany developed a salicylic acid derivative, aspirin (or acetylsalicylic acid) for commercial use. $1895 \mathrm{AD}$

In $1895 \mathrm{AD}, \mathrm{X}$-rays were discovered by the physicist Wilhelm Röntgen. "X-rays", though many referred to these as "Röntgen rays" (and the associated X-ray radiograms as, "Röntgenograms") for several decades after their discovery, even to this day in some languages, including Röntgen's native German. This is regarded as one of the most important discovery in medical science. (Rontgen, 1895).

\section{- 1903 AD}

Dutch physiologist, professor and inventor Willem Einthoven invented the eponymous Einthoven galvanometer. It had a thin metallic wire held between two electromagnets, with the wire connected to electrodes on the patient's chest, and the patient's hands and one foot bathed in salt-water tubs. This device weighed 600 pounds and produced the first form of electrocardiogram. Einthoven was awarded the Nobel Prize in physiology and medicine for the invention of electrocardiograph (Figure 4). (Snellen 1995).

\section{- 1912 AD}

The discovery of the vitamins was a major scientific accomplishment in our accession of health and disease. In 1912 $\mathrm{AD}$, Casimir Funk primarily coined the term "vitamine". The major period of discovery commenced in the beginning nineteenth century and completed at the mid-twentieth century. The complexity of each vitamin was revealed through the work and contributions of epidemiologists, physicians, physiologists, and chemists. Research on the vitamins that are annexed to major deficiency syndromes began when the germ theory of disease was conventional and dogma held that only four nutritional factors were essential: proteins, carbohydrates, fats, and minerals. Clinicians in due time detected scurvy, beriberi, rickets, pellagra, and xerophthalmia as specific vitamin deficiencies, rather than diseases due to infections or toxins. Our understanding of the vitamins continues to evolve from the initial period of discovery (Semba, 2012). 


\section{- 1921 AD}

The story of the discovery of insulin has been well chronicled beginning with a young physician, Frederick Banting, in London, Ontario, Canada, imagining that it might be possible to isolate the internal secretions of the pancreas by ligating the pancreatic ducts to induce atrophy of the acinar cells and thereby minimize contamination of the tissue extract with digestive enzymes. In the

Table 1 :The discovery dates of the vitamins and their sources

\begin{tabular}{|l|l|l|}
\hline Year of discovery & Vitamin & Food source \\
\hline 1910 & Vitamin B1 (Thiamine) & Rice bran \\
\hline 1913 & Vitamin A (Retinol) & Cod liver oil \\
\hline 1920 & Vitamin B2 (Riboflavin ) & Meat, eggs \\
\hline 1920 & Vitamin D (Calciferol) & Cod liver oil \\
\hline 1920 & Vitamin C (Ascorbic Acid) & Citrus, most fresh foods \\
\hline 1922 & Vitamin E (Tocopherol) & Wheat germ oil, unrefined vegetable oils \\
\hline 1926 & Vitamin B12 (Cobalamins) & Liver, eggs, animal products \\
\hline 1929 & Vitamin K1 (Phylloquinone) & Leafy green vegetable \\
\hline 1931 & Vitamin B5 (Pantothenic acid) & Meat, whole grain \\
\hline 1931 & Vitamin B7 (Biotin) & Meat, dairy products, eggs \\
\hline 1934 & Vitamin B6 (Pyridoxine) & Meat, dairy products \\
\hline 1936 & Vitamin B3 (Niacin) & Meat, eggs, grain \\
\hline 1941 & Vitamin B9 (Folic acid) & Leafy green vegetables \\
\hline
\end{tabular}

\section{- $\quad 1924$ AD}

German physiologist and psychiatrist Hans Berger recorded the first human EEG in 1924. Expanding on work previously conducted on animals by Richard Caton and others, Berger also invented the electroencephalogram (giving the device its name), an invention described "as one of the most surprising, remarkable, and momentous developments in the history of clinical neurology". His discoveries were first confirmed by British scientists Edgar Douglas Adrian and B. H. C. Matthews in 1934 and developed by them (Jacks, 2003).

\section{- $\quad 1928 \mathrm{AD}$}

The discovery of penicillin is attributed to Scottish scientist and Nobel laureate Alexander Fleming in 1928. He showed that, if Penicillium Rubens were grown in the appropriate substrate, it would exude a substance with antibiotic properties, which he dubbed penicillin. This observation began the modern era of antibiotic discovery. The development of penicillin for use as a medicine is attributed to the Australian Nobel laureate Howard Walter Florey together with the German Nobel laureate Ernst Chain and the English biochemist Norman Heatley. The isolation of 6-APA, the nucleus of penicillin, allowed for the preparation of semisynthetic penicillin's, with various improvements over benzyl penicillin (bioavailability, spectrum, stability, tolerance). (Fleming 1929, Jos.H, 2011).The first major development was ampicillin, which offered a broader spectrum of activity than either of the original penicillin's. Further development yielded $\beta$-lactamaseresistant penicillin's, including flucloxacillin, dicloxacillin, and methicillin. These were significant for their activity against $\beta$ lactamase-producing bacterial species, but were ineffective against the methicillin-resistant Staphylococcus aureus strains that subsequently emerged (Harold 1969). Another development of the line of true penicillin's was the antipseudomonalpenicillin's, such as carbenicillin, ticarcillin, and piperacillin, useful for their activity against Gram-negative bacteria. However, the usefulness of the $\beta$ lactam ring was such that related antibiotics, including the mecillinams, the carbapenems and, most important, the winter of 1922, Banting and Best treated their first human patient, a young boy, whose life was saved by the treatment. Banting and J.J.R. Macleod both shared the Nobel Prize in 1923. Best was a medical student lab assistant and J. Collip was also brought in as a protein biochemist to assist with the isolation. Banting shared his part of the prize with Best, Macleod shared his part with Collip. (Robert 1923) 
To analyze the "X-ray marrow" protocol, which seemed to possess the better applicability for human employment, scientists tested on mice and rabbits. Employing sub-lethal or lethal doses of total body X-ray, followed by marrow infusions from solitary or multiple-donors, they were able to achieve a number of longsurviving skin allografts (Wilson 1959).

Following these first analyses the application of N,N'N'triethylenethiophosphoramide also called Thio-TEPA as an alternative for complete body X-ray treatment was tested in 1958.Around the same time, success came with the use of immunosuppressive drugs by Schwartz and Dameshek in 1959 (Schwartz, 1959). This treatment with 6-mercaptopurine prevented the rabbits from producing antibodies against human albumin antigen. This "drug induced acceptance" of the antigen continued following drug treatment was ceased, even though the animals could act normally against another types of protein antigen, bovine gamma globulin. Therefore the acceptance seemed to be specific for antigens present at the same time period as the drug administration. Roy Calne in London (Calne 1960) and Charles Zukoski in Virginia (Zukoski 1960) analyzed this drug in the canine renal transplant model and had motivating results. The analytical drug, BW-322, the imidazole derivative of 6mercaptopurine, seemed to adhere the best therapeutic index. This drug is now prescribed as azathioprine, or Imuran, and had been utilized throughout the world to assist organ transplantation for 20 years. Now newer drugs are achievable and under analysis to continue their benefit and lower toxicity.

The first renal transplant recipient to receive azathioprine was an adult transplanted with an unrelated kidney in March 1961. The transplant functioned well for over one month, however the patient died of drug toxicity because the dosage used in dogs proved to be toxic for humans.

A patient, transplanted in April 1962, was treated with azathioprine following a cadaveric renal allograft. He lived for over one year and was the world's first successful unrelated renal allograft recipient (Murray 1963). Dr. Willard Good-win, at the University of California in Los Angeles, contemporarily commenced the use of corticosteroids as an additionally accessory to the treatment (Goodwin 1963)

The accomplishment with renal allografts directly led to attempts to transplant other organs. Moore developed the surgical approach for orthotropic canine liver transplantation (Moore 1959), the model approach applied by Starzl for first accomplished human liver allografts (Starzl 1968).

Single- and double-lung transplantation have resulted, as well as compounded heart-lung transplants. Transplantation of the pancreas, with or without an accompanying renal graft, is normally performed. Multiple organ transplants in combination with liver and parts of the intestinal tract have also been accomplished. (Dong 1972). In the 1960s surgeons performs the first human liver, human lung, human pancreas transplant and cochlear embedding (Starzl, 1963).

\section{- $1967 \mathrm{AD}$}

Norman Shumway is widely regarded as the father of heart transplantation, although the world's first adult human heart transplant was performed by Christiaan Barnard in South Africa utilizing the techniques developed and perfected by Shumway and Richard Lower. Barnard performed the first transplant on Louis Washkansky on December 3, 1967 at the Groote Schuur Hospital in Cape Town South Africa. Adrian Kantrowitz performed the first pediatric heart transplant in the world on December 6, 1967 at Maimonides Hospital (now Maimonides Medical Center) in Brooklyn, New York barely three days after Christiaan Barnard. Norman Shumway performed the first adult heart transplant in the United States on January 6, 1968 at the Stanford University
Hospital.(Elmqvist, 1986.) In 1982 surgeons implant first artificial heart in the human body (Apple, 1996; Blakeslee, 2009).

\section{- $\quad 1987 \mathrm{AD}$}

The first handheld computers emerged, and were found to have uses in healthcare. Mobile electronic devices were identified and described as tools for research. Suggested uses for clinicians and patients care were developing for areas such as disease prevention, health education and health promotion - extensively covering major areas like lifestyles (nutrition, diet, physical and mental activities), self-diagnosis, management of infectious and chronic degenerative diseases, and information searches in search engines. By hooking a variety of devices onto a smartphone, a clinician may one day be able to give a complete physical - for example with devices to take photos of eardrum, the back of eye, listening to heartbeat, charting lung functions etc. These mobile medicines might also help doctors care for patients in new ways, and for example tracking of a person's blood pressure and heart rate could help treat and prevent CVS disease.

\section{MEDICAL PRESENT ERA (2000-2014)}

Rapid advances in medicine have greatly improved the ability of physicians to diagnose and treat a variety of diseases. This enhanced ability often leads to improved outcomes for patients. The Human Genome Project was carried out in this era. In this project, scientists determined the sequence of the chemical base pairs which make up human DNA, and identified and mappedapproximately20, 000-25,000 genes of the human genome, from both a physical and functional standpoint. While a working draft of the genome was announced in 2000 and completed in 2003, further, more detailed analysis still being published(Raju, 1999).Moreover the tele-surgery technique has been introduces, allowing surgeons to robotically operate on a patient while being at a significant distance from the operating table(Holt, 2004). During this time period, scientists also invented a medical device comprising an implant for the treatment of an affection of anatomical ducts. This device improved the conditions of the setting and holding of an implant in an anatomical duct, mainly in the case of a vascular implant or endoprosthesis.(Chevillon,2001)
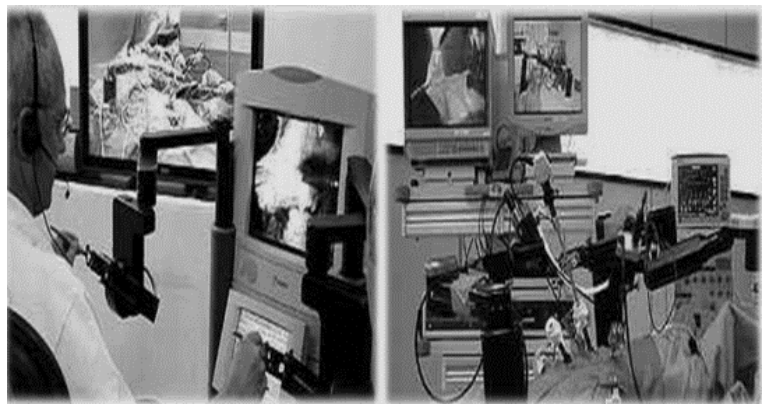

\section{- $\quad$ Surgeon Patient}

In 2003, physicians introduced a new method for the therapeutic treatment of the brain: deep brain stimulation. The system employs electrodes implanted in specific regions of the brain delivering electrical pulses (Tosaya, 2003). Engineers have even developed a "bionic" eye, an epiretinal prosthesis system for patients. This system interfaces the biological tissue with electronic sensors and processors to give a degree of vision. This strategy or that of bionic glasses may allow the blind to see (Ong, 2012). In 2005 the world's first partial face transplant on a living human was carried out in France. In Spain the world's first full face transplant was completed in 2010.

In 2006 one of the scourges of humanity was addressed in a novel fashion: the first vaccine to prevent cancer was introduced. The 
human papilloma virus (HPV) vaccine prevents sexually transmitted infection and in turn cervical cancer. More than forty types of HPV that can infect the genital areas of males and females, and some other HPV types can also infect the mouth and throat, implicated in head and neck cancers. Several types of HPV can be prevented by this vaccine. Two new rotavirus vaccines, replacing an earlier vaccine which had been withdrawn, were approved by the FDA (Steinbrook, 2006; Angel, 2007). These vaccines prevent the leading cause of infant diarrhea, a major cause of morbidity and mortality in infants.

In 2011 the FDA approved breast tomosynthesis, a new diagnostic imaging technology. It can be performed along with a traditional mammogram for more accurate screening for cancer. The x-ray arm of the machine makes a quick arc over the breast, taking dozens of images at a range of angles that are then merged into a 3D image (Kopans, 2011).This provides better diagnostic images. Weight-loss surgery can help patients with type 2 diabetes reverse their disease. Doctors began investigating this operation as a treatment for obese patients with poorly controlled type 2 diabetes in 2012(Fitzer, 2012)

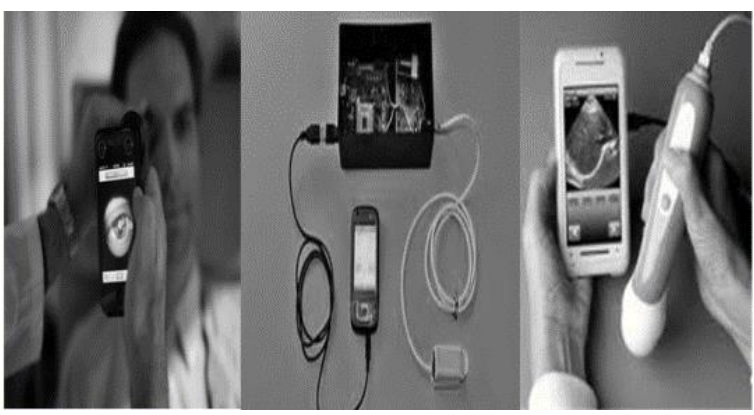

Figure 5: Different Devices Attached to Smartphone's for Monitoring

In 2013 doctors in the US made medical history by effectively treating a child born with the Human Immunodeficiency Virus (HIV), the first time such a case has been documented (Anna,2013). Also in 2013, scientists grew a kidney in the laboratory and showed that it works when implanted into a living animal. This work is an important step towards the longer-term goal of growing personalized replacement kidneys that could be transplanted into people with kidney failure (Coghlan, 2013).

\section{MEDICAL FUTURE ERA}

The future of medicine and surgery is full of possibilities. Several promising areas are highlighted here.

\section{Point-of-care testing}

Automated handheld diagnostic appraisal is intended to alleviate the 'time-to-result' to five to ten minutes. These devices aim to do so by speeding up the biomarker measurement approach and allowing specific results to be generated at the point-of-care rather than in a centralized laboratory, i.e. close to the patient during the first patient-physician intercommunication - where it can be applied to make a clinical determination. The person operating the test is not a laboratory expert but for instance a physician or a nurse. Key success factors for new point-of-care tests include the analytical action which should be as accurate as laboratory results, though not difficult to use, and the connectivity to the hospital IT infrastructure to access the adjoining patient data coveted for fast clinical decision making (Madeleine et al 2013).

\section{Nanotechnology in Medicine-Nano medicine}

The application of nanotechnology to medicine opens up new possibilities. Some approaches are just envisaged; others are at various stages of investigation; some are actually in use today. Nanotechnologies in medicine comprise contemporary nanoparticle fabrication, and longer range research that foresees the use of manufactured nano-robots to make repairs at the cellular level (sometimes called "nanomedicine"). Whatever it could be called, the use of nanotechnology in the field of medicine could revolutionize the way disease are determine, treatment, and many approaches only anticipated a few years ago are making excellent potential to be practical in the near future (Mitsunobu 2013).

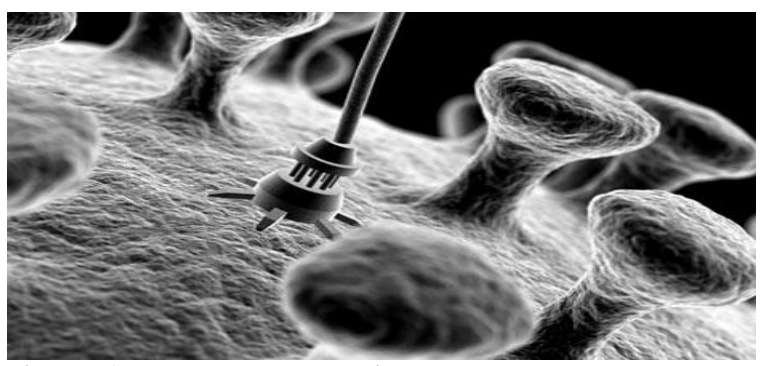

Figure 6: Targeted drug delivery through nanotechnology. Nanotechnology will helps us in achieving a better and safer life.

\section{Medicine Application in Nanotechnology: Drug Delivery}

One approach of nanotechnology in contemporary medicine involves applying nanoparticles to carry drugs, heat, and light or toxins to specific types of cells (such as cancer cells). Particles are fabricated so that they are attracted to the cells of interest, and can then deliver drugs, poisons or macromolecules to those cells. This approach halts the development of disease, while avoiding damage to vital cells in the body.

For example, nanoparticles that convey chemotherapy drugs accurately to cancer cells are under development. Analyses are in progress for targeted contribution of chemotherapy drugs and their application to treatment of cancer patients is pending. One company has announced the pending results of a Phase 1 Clinical Trial of their first targeted chemotherapy drug and another company has published initial results of a Phase 1 Clinical Trial for their first targeted chemotherapy drug.

Other approaches are also under development to deliver chemotherapy drugs directly to cancer cells; using externally excited nanoparticles to deliver heat to the cell; and gold nanorods to which DNA strands are attached: the DNA strands act as a scaffold, holding together the nanorod and the chemotherapy drug. When Infrared light brightens the tumor the gold nanorod is energized by infrared light, converting it into heat. The heat both releases the chemotherapy drug and helps kill the cancer cells.

Researchers have developed nanoparticles that release insulin in reaction to a glucose level surge. The nanoparticles contain both an enzyme and insulin. In high glucose levels, the enzyme is activated and releases the insulin. In lab tests these nanoparticles were able to regulate blood sugar levels for several days.

Researchers are additionally developing a nanoparticle to combat viruses. The nanoparticle does not precisely destroy virus molecules, but carries an enzyme that inhibits the reproduction of viruses in the patients' bloodstream. Researchers are developing a vaccine strategy to amplify the immune response caused by vaccines by linking the vaccine antigens to a DNA nanostructure 
that delivers the vaccine molecules to the specific cells that are key in triggering an immune response (Rosenblum 2013).

\section{Medicine Application in Nanotechnology: Therapy Techniques}

Researchers are exploring "nanosponges" that capture toxins and carry them from the blood-stream. The nanosponges are polymer nanoparticles covered with a red blood cell (RBC) membrane. The red blood cell membrane allows the nanosponges to travel independently in the bloodstream and attract the toxins.

Investigators have developed a method to generate sound waves that can destroy tissue, which may be applicable for non-invasive surgery. They excite a lens coated with carbon nanotubes to convert light from a laser into focused sound waves. The technique would be able to destroy tumors or other diseased tissues without damaging healthy tissue.

Bismuth nanoparticles are being designed which will focus radiation used in radiation therapy to treat cancer. Test show that the bismuth nanoparticles would increase the radiation dose to the tumor by 90 percent. Nanoparticles composed of polyethylene glycol-hydrophilic carbon clusters (PEG-HCC) have been shown to absorb free radicals at a much higher rate than the native proteins our body uses for this function. This adeptness in absorbing free radicals may reduce the damage caused by the release of free radicals after a brain injury. Targeted heat therapy is being developed to destroy breast cancer tumors. In this method antibodies that are strongly attracted to proteins produced in one type of breast cancer cell are attached to nanotubes, causing the nanotubes to accumulate at the tumor. Infrared light from a laser is absorbed by the nanotubes and produces heat that destroys the tumor (Houria 2011).

Nano-fibers can also stimulate the production of cartilage in damaged joints. Similarly, nano-fiber layers produced from biopolymers (chitosan, gelatine, collagen, polykaprolakton, etc., or combinations of these materials) can be used as a wound dressing for significant support of the wound healing process. On the basis of results realized from in vitro and in vivo experiments, nanofiber materials have shown significant benefits. When using nanofiber material on contaminated wounds, it is possible to add antibacterial material and drugs to the nano-fiber structure Granulation and re-epithelialization of new dermal tissue can be enhanced by adding growth factor, and adding other materials which support proliferation of dermal tissue. The wound can be covered by a single nano-fiber layer or it is possible to incorporate anano-fiber layer onto other carriers and cover the wound with this composite material. (Fisher et al 2012).

\section{Medicine Application and Nanotechnology: Diagnostic Techniques}

Research has elucidated a method for using nanoparticles in the early diagnosis of infectious disease: the nanoparticles attach to biomarkers in the blood stream marking the beginning of an infection. When the sample is analyzed by Raman spectroscopy, a signal can be acquired from very low marker levels, revealing the infectious disease at a very early stage.

Researchers are developing a nanoparticle that is hoped to make very early diagnosis of cancer tumors easier. When the nanoparticles contact a cancerous tumor, the nanoparticles bind "biomarkers" proteins. Since each nanoparticle binds numerous proteins a high absorption of these biomarkers will occur even at very early stages of cancer, allowing early detection of the disease. A test for early diagnosis of kidney damage is also being developed. The method applies gold nanorods engineered to accompany the type of protein released by damaged kidneys. When the protein accumulates on the nanorod, the color of the nanorod changes. The test is conceived to be conducted quickly and economically for early disease detection.

A method for early diagnosis of brain cancer is under development that uses magnetic nanoparticles and nuclear magnetic resonance technology (NMR). The magnetic nanoparticles attach to particles in the blood stream called micro-vesicles which originate in brain cancer cells. NMR is then used to detect these microvesicle/magnetic nanoparticle clusters, allowing an early diagnosis. Carbon nanotubes and gold nanoparticles are being used in a sensor that detects a protein specific to oral cancer. Tests have shown that this sensor is accurate in detecting oral cancer, and gives results in less than an hour.

Silver nanorods can be used in a diagnostic system to separate viruses, bacteria and other microscopic components of blood samples, giving clearer Raman spectroscopy signals. This procedure has been demonstrated to allow identification of viruses and bacteria in less than an hour (Wei etal 2012).

Medicine Application and Nanotechnology: Anti-Microbial Techniques

One of the earliest nanomedicine applications was the application of nanocrystalline silver which is an antimicrobial agent for the treatment of wounds; a cream containing this nanomaterial has been shown to fight staph infections. The nanoparticles induce nitric oxide gas which is known to kill bacteria. Research on mice has shown that using the nanoparticle cream at the site of staph abscesses alleviated the infection.

A burn dressing that is coated with nanocapsules containing antibiotics can aid in recovery. If pathogenic bacteria have infected a wound, the nanocapsules rupture and release the antibiotics. This allows much faster treatment of a burn and reduces the number of times a dressing has to be changed. Bacterial infections can be abolished within minutes, instead of needing treatment with antibiotics over a period of weeks (Wei et al 2012).

\section{Targeted Viral Therapy Destroys Breast Cancer Stem Cells in Preclinical Experiments}

The diameter of viruses is in the nanometer size range. An affirming new treatment for breast cancer being developed at Virginia Commonwealth University Massey Cancer Center and the VCU Institute of Molecular Medicine has been shown in cell culture and in animal models to selectively kill cancer stem cells at the beginning tumor location, and additionally in distant metastases with no toxic effects on healthy cells. Cancer stem cells are key to a cancer's adeptness to recur following accepted chemotherapies and radiation therapy. They can multiply and ascertain become new tumors that are often therapy resistant. The gene, melanoma demarcation affiliated gene-7 (mda-7) has been appeared to articulately impacts two forms of cell suicide known as apoptosis and toxic autophagy, arranges the conception of new blood vessels and also plays a role in accelerating cancer cell evasion by the immune system. In the unveil assay, researchers applied a recombinant adenovirus vector engineered with adapted Ad.mda-7 to deliver the mda-7/IL-24 gene to the tumor, resulting in the expression of the mda-7 protein in the tumor cells. "Therapy with the mda-7/IL-24 gene is in a phase I clinical trial involving patients with advanced cancers, and prior studies in laboratory have shown that the gene could also be arrogant against breast, prostate, lung, colorectal, ovarian, pancreatic and brain cancers,". The researchers detected that infection of human breast cancer cells with the adenovirus curtailed the proliferation of breast cancer stem cells without affecting normal breast stem cells. It was also shown to induce a stress response in the cells that led to apoptosis by disrupting Wnt/B-catenin alarming, a process cells use to convey signals related to survival. In mouse models, the 
therapy admonished abolished the amplification of tumors generated from breast cancer stem cells and also killed cancer cells in distant, un-injected tumors. Since detecting the mda-7/IL-24 gene, scientist have worked to develop better ways to deliver it to cancer cells, including two cancer terminator viruses known as Ad.5-CTV and Ad.5/3-CTV. Cancer terminator viruses may be a better option because they are conceived to replicate only within cancer cells, and can be engineered to bear immune-modulating and toxic genes such as MDA-7/IL-24. Coupled with a novel stealth delivery discipline known as ultrasound-targeted micro bubble abnegation (UTMD), researchers can now systemically deliver viruses and therapeutic genes and proteins articulately to tumors and their surrounding tissue eat both primary and metastatic tumor sites. UTMD uses microscopic, gas-filled bubbles that can be paired with viral therapies, therapeutic genes and proteins, and imaging agents, and can then be targeted/delivered to a site via ultrasound. This approach has already been successful in experiments utilizing UTMD technology and mda-7/IL-24 gene therapy in prostate and colorectal cancer models (Sujit et al 2013).

\section{Oncolyticvirotherapy}

Oncolyticvirotherapy exploits live viruses with selective tropism for cancerous cells and tissues to treat cancer, the field has progressed considerably as a result of both the successes and failures of previous and on-going clinical trials for various cancers. These studies indicate that oncolytic viruses are remarkably safe and more efficacious when virus replication stimulates sustained antitumor immune responses. In the future, viro therapy should be combined with immune modulatory reagents that target immune tolerance to established cancers (John B 2014).

\section{Medicine Application and Nanotechnology: Cell Repair}

Lastly with regard to nanotechnology, nanorobots might be programmed to repair particular diseased cells, functioning in a parallel way to antibodies in our natural healing processes.

\section{Human Organs Grown In the Animals}

Japanese scientists say they will be able to raise human organs in animals within a year, with the assignment of new guidelines that will allocate the action. Human stem cells would be embedded into a pig embryo to commence a "chimeric conception" that could grow into a healthy, animal with a human organ that grows as the animal matures. These scientists have already successfully implanted and grown rat stem cells in mouse embryos (Takanori et al 2013).

\section{Production of Blood-Forming Stem Cells in the Lab}

Hematopoietic stem cells produce millions of new blood cells in the adult body every day. By transferring four genes into mouse fibroblast cells, researchers have been able to produce induced pluripotent stem cells. It is hoped that a variety of human tissue cells will similarly be capable of being developed from induced pluripotent stem cells. These studies may lead to the development of patient-specific stem cells therapies. Cells amplified in a petri dish and induced into colonies of mature cells. This field leads to hope for a wholly novel treatment for blood disorders (Rosania 2012).

Prospective Uses of 3D Printing In Medicine Cutting Down the Backlogged Kidney Transplant List

Eighty percent of the approximately113, 000 Americans on the organ transplant list are in need of a new kidney: only 30,000 kidney transplants are conducted in the U.S. every year. It is estimated that around 4,000 deaths annually occur due to the lack of kidneys for transplantation. It is hoped that with the use of "Bio-
Ink" and 3D printers that could all change: kidneys for transplant will be printed. Researchers have been applying a "bio printer" to imitate living tissue structures. The long-term goal of researchers is to commence transplanting printed human organs in some five to 10 years. (Matthew 2013).

\section{Cure Diabetes by Creating Entirely New Organs}

One of the most promising research areas is bio printing a glucosesensitive pancreatic organ that can be grown in a laboratory and transplanted anywhere inside the body to adjust the glucose level of blood. Considering the epidemic-level of diabetes in the United States and the affiliated health care costs of the disease, this would be a true medical overturning, centrally abolishing the disease. And if researcher could create that kind of technology, it could conceivably be adapted to treat cancers and other chronic conditions (Matthew 2013)

\section{Grafting Skin on to Burn Victims}

The current approach of skin grafting requires the aggravating abscission of skin from a candid area of the patient's body. But researchers are developing a method of loading skin cells and other polymers into a $3 \mathrm{D}$ printer to create cohesive layers of skin. Exceptionally, the team applied a simplified 3D printer that costs far less than the average $\$ 200,000$ for skin grafting, and claim that their printer can produce tissue for 1/1000th of that cost "even by the most conservative estimates" (Matthew 2013).

\section{Making Prostheses Resemble the Original Missing Limb}

This is an area in which there has already been definitive furtherance with 3D printers and acquires major benefits for the patient along with quality of life. The adversity with current prostheses is that they abrade down, don't absolutely form to patients' limbs, and can display a stigma for patients who need them. But scientists Innovations have created prosthetic coverings "that absolutely duplicate the sculptural consistency along with function of the wearer's remaining limb," and can even be customized to accept to the patient's coordination caste. Authentically creating a completely new limb would be ambitious but considering that doctors contemporarily changed 75 percent of a man's skull with a 3D-printed implant that might not be out of the belief, either (Matthew 2013).

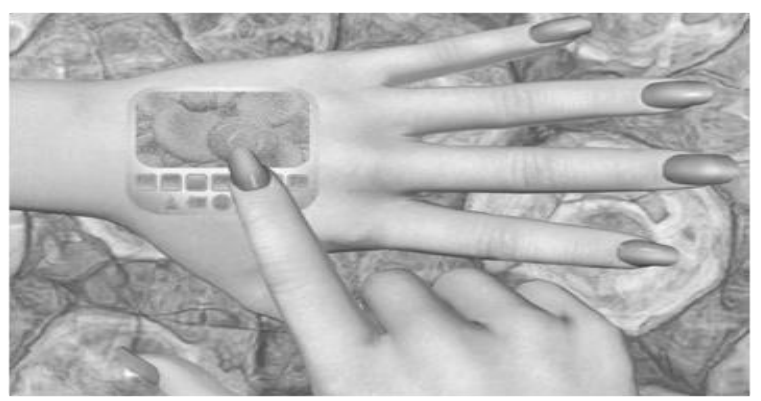

Addressing dental health needs. Availability of dental treatment is limited for the poor. But the application of $3 \mathrm{D}$ printing in orthodontics could change that by bringing about dental interventions with far less cost than is current. A digital scan of the inside of a patient's mouth and a 3D printer is all that would be expected to be needed to fabricate crowns, bridges, and dentures. It is also less invasive and more accurate, making it unnecessary to create physical molds of patients' mouths (Matthew 2013).

\section{CONCLUSION}

In the coming years, prospective medicine will observe patients electronically and treat them remotely. It is beingbelieved that the 
general practitioner will have a wide variety of medicines and related technologies to choose from to treat a lethal disease. Tumors will be destroyed by 'smart' treatments that will leave neighboring tissues undamaged. Genetic susceptibility to disease will be determined, treated and thus prevented. One of the needs for community wellbeing is to allocate resources economically. Many of the new technologies will allow better care while reducing costs. Medicine is already in the era of Big Data. Scientist-led creation of large databases, genomic and other, has created the large-scale generation of public source information that already directs treatment: these developments lie at the heart of this future revolution (Pevsner, 2009). Our capability to discover genome meaning, increasing in specificity as each succeeding genome is sequenced (Beveridge, 2002), will lead to treatments unforeseen today. Geneticists are aiding in the creation of more effective therapy, including even correcting genetic defects. Modern molecular genetics creates opportunities to create animal models of diseases and to learn what happens at the molecular level in disease. We continue to learn more about our microbial adversaries, their genetics and behavior. The remarkable advance of biomedical translational research is integrating proteomics, genomics, and treatment. Patient information databases and disease registries link outcomes with scientific knowledge (Nobel, 2008). Recently, microarray technology has led to the ability to study the expression of tens of thousands of genes in a single hour, when in the recent past the establishment of the expression patterns of one or two genes per month was an achievement (Collins, 2003; Church, 2009). The scientific world is evolving towards biomedical (or biological) micro-electromechanical systems (BioMEMS). This development will build a variety of sensors and integrate computing power to deliver rapid diagnosis and instantaneous patient monitoring. Things are moving toward actually scientist will be able to modify gene mutations at the level of DNA itself. We are in the era of personalized medicine (Grayson, 2004; Bashir, 2004). New research is also focussing on powerful cancer drugs known as alkylating agents which damage DNA by attaching molecules containing carbon atoms to it, destroying tumor cells. Chemotherapy will be improved by understanding the specific genome of a cancer, targeting treatment, and, by measuring the enzyme levels in the patient, reducing side effects and also maximizing drug effectiveness (Demain, 2009; Henderson, 1998).

Future surgery may allow the growing artificial limbs, which will be able to work as normal limb. Similarly like limbs researchers look forward to have a better understanding of how each part of the heart works. The hope is to make possible effective replacements to employ in transplants. Scientists are also working to develop organs and other body parts from stem cells (Fridell, 2005). Wireless sensor placement inside the human body, which can observe and evaluate any pathological or physiological, effect of treatment will guide us in surgery. Sensors can do incredible things: they can monitor chronic maladies and provide distant warning of incipient health crises (Furtado, 2009). These sensors can detect seizures, heart attacks, diabetic reactions, etc., and allow timely intervention. The up-and-coming field of regenerative medicine may one day revolutionize the plan for treatment of CVS and of neurological disorders, solve the organ donor problem, and completely restore damaged muscles, tendons and other tissues (Vanantwerp, 2012). Basic and applied researchers are learning to give the human body a kind of treatment kit made of different proteins, fibers, cells or semi-specialized stem cells that are already found in adult patients, allowing the body to take over from there. Biosensors can be incorporated into smart phones to do everything from diagnosing malaria to investigating electrolytes. Mobile cameras will take a picture of a membrane lesion and use an algorithm to conclude if it is melanoma; sampling breath might detect lung cancer. A state-of-the-art "tattoo" worn on the skin can be used by your cell phone to measure your blood sugar levels.
Specialists will look forward to convenient, handheld CT, X-rays and MRI scanners in the future. Future machines will have supersensitive atomic magnetometers, able to distinguish the tiniest magnetic fields, replacing the gigantic magnets that are presently used for MRI. An increasing number of practitioners believe that intestinal diseases can be treated with fecal transplants. This involves taking healthy fecal matter from a donor, mixing it with a saline solution, and then introducing it into the patient's digestive tract, where "good" micro-biota aid in healing the tissue.

Scientist believe that Medical practice is continuously altering and developing in response to new information and focusing on new machinery. The expectations of medicine hold great promise. The challenge will be to temper our enthusiasm with good quality judgment. We can't suppose unalloyed benefit from every technological advance.

\section{DISCLAIMER}

We have tried to include all the possible past, present and future, but still we might have missed things. The purpose of this review is to give a taste of the history and what future of medicine holds promise for man. This is not the complete history and nor the full picture of present and future.

\section{CONFLICT OF INTEREST}

All the authors disclosed that there is no Conflict of interest associated in the preparation of this review article.

\section{ACKNOWLEDGMENT}

We would like to acknowledge Saima Khan \& Zain Azher.

\section{REFERENCE}

1. Fenner, F. (1976). The Eradication of Smallpox1. Director, 2.

2. Fernald, M., A. Kinsey, and R. Rollins. 1943. Edible Wild Plants. Harper \& Row, NY.

3. Fishchenko, AIa; Khimich, SD (1986), "Modification of the Hippocratic cap- shaped bandage", KlinKhir 1 (72). PMID 3959439

4. Fisher E, Marianne Boenink, Simone van der Burg and Neal Woodbury. Responsible healthcare innovation: anticipatory governance of nanodiagnosticsfor theranostics medicine. Expert Rev. Mol. Diagn. 12(8), 857-870 (2012).

5. Fitzer, M. A., de la Torre, R., Schauer, P. R., Kashyap, S. R., \&Wolski, K. (2012). Glycemic management of type 2 diabetes mellitus. The New England journal of medicine, 367(2), 181.

6. Fleming A (1929) On the antibacterial action of cultures of a Penicillium, with special reference to their use in the isolation of B. influenzae. British Journal of Experimental Pathology 10: 226-236.

7. Forrest, R. D. (1982). Early history of wound treatment. Journal of the Royal Society of Medicine, 75(3), 198

8. Fridell, R. (2005). Decoding life: Unraveling the mysteries of the genome. Twenty-First Century Books.

9. Furtado, H., \&Trobec, R. (2009). Wireless Sensor Networks for Minimally Invasive Surgery. In Proceedings of the The National Symposium of Telecommunications and TeleinformaticsKSTiT.

10. Georges-Berthier. (1914). Le mecanismecartesienet la physiologie au XVIIe siecle. Isis, 37-89.

11. Goel, A., \&Aggarwal, B. B. (2010). Curcumin, the golden spice from Indian saffron, is a chemo sensitizer and radio sensitizer for tumors and chemo protector and radio protector for normal organs. Nutrition and cancer, 62(7), 919-930. 
12. Goodwin WE, Kaufman JJ, Mims MM, et al. Human and renal transplantation. I. Clinical experiences with six cases of renal transplantation. J Urol 1963; 89:13.

13. Grayson, A. R., Shawgo, R. S., Johnson, A. M., Flynn, N. T., Li, Y., Cima, M. J., \& \& Langer, R. (2004). A BioMEMS review: MEMS technology for physiologically integrated devices. Proceedings of the IEEE, 92(1), 6-21.

14. Greenhill, W. A. (1843). Address to a medical student [by WA Greenhill]

15. Gunderson, E. (2009). Noxphilologiae: AulusGellius and the fantasy of the Roman library. University of Wisconsin Press.41, Rufus of Ephesus, De Appell. Part. etc. p. 65

16. Harold C Neu. Effect of 3-Lactamase Location in Escherichia coli on Penicillin Synergy. Applied Microbiology, June 1969, p. 783-786, Vol. 17, No. 6.

17. Harris, J. C., Cottrell, S., Plummer, S., \& Lloyd, D. (2001). Antimicrobial properties of Allium sativum (garlic)Applied Microbiology and Biotechnology,57(3), 282-286

18. Harvey, S. C. (1942). The History and Evolution of Surgical Instruments. The Yale Journal of Biology and Medicine, 15(1), 133

19. Henderson, N., Lacy, S., OHare, C., Hartley, J., McClean, S., Wakelin, L., ...\& Robins, D. (1998). Synthesis of new bifunctional compounds which selectively alkylate guanines in DNA. Anti-cancer drug design, 13(7), 749-768.

20. Hickey, T.M., O'Connell, E. (2003) revision, CPT (Center for the Tebtunis Papyri). Bancroft Library, University of California, Berkeley. Archived from the original on 12-10.

21. Hoeppli, R. (1956). The knowledge of parasites and parasitic infections from ancient times to the 17th century. Experimental Parasitology, 5(4), 398-419.

22. Holt, D., Zaidi, A., Abramson, J., \&Somogyi, R. (2004). Telesurgery: advances and trends. University of Toronto Medical Journal, 82(1), 52-5

23. HouriaBoulaiz, Pablo J. Alvarez, Alberto Ramirez, Juan A. Marchal, Jose Prados , Fernando Rodríguez-Serrano. Nanomedicine: Application Areas and Development Prospects. Int. J. Mol. Sci. 2011, 12, 3303-332

24. John Bell and Grant McFadden. Viruses for Tumor Therapy. Cell Host \& $\quad$ Microbe, March, 2014.

25. John, F. N. (1996) "Ancient Egyptian Medicine". (Normal, OK: University of Oklahoma Press), 26-28.

26. Jones, W. H. S. (1868), Hippocrates Collected Works I Cambridge Harvard University Press, retrieved September 28, 2006.

27. Jos Houbraken, Jens C. Frisvad, and Robert A. Samson. Fleming's penicillin producing strain is not Penicilliumchrysogenum but P. rubens. 2011 IMA Fungus • volume $\quad 2 \cdot$ no $\quad 1: 87-95$

28. Kelley, J. J. (1970). History of ocular prostheses. International Ophthalmology Clinics, 10(4), 713-719.

29. Konomi, N., Lebwohl, E., \& Zhang, D. (2002). Comparison of DNA and RNA e xtraction methods for mummified tissues. Molecular and cellular probes, 16(6), 445-451.

30. Kopans, D., Gavenonis, S., Halpern, E., \& Moore, R. (2011). Calcifications in the breast and digital breast tomosynthesis. The breast journal, 17(6), 638-644.

31. Krieg, J. C. (1995). Chiropractic manipulation: an historical perspective. The Iowa Orthopaedic Journal, 15, 95.

32. Lang S, Murray JE, Miller BF. Homotransplantation of ischerrlic kidneys into dogs with experimentally produced impairment of renal function. PlastReconstrSurg 1956; 17:211.

33. Lobelia. EBSCO Complementary and Alternative Medicine (CAM) Review Board. January 2006. Retrieved 200709-12

34. Loudon, Irvine (2007).Western Medicine: An Illustrated History. Oxford University Press. ISBN 9780199248131

35. Madeleine H.E. Bruins Slot, Geert J.M.G. van der Heijden, Saskia D. Stelpstra, Arno W. Hoes, Frans H. Rutten,. Point-of-care tests in suspected acute myocardial infarction: A systematic review. Int J Cardiol. 2013 Aug 15

36. Marry, A. (2004) "Ancient Egyptian Medical Papyri"". Ancient Egypt Fan: Articles.

Indigo.ie/ marrya.Archived from the original on 2004-02-24

37. Matthew B Hoy. 3D printing: making things at the library. Med Ref Serv Q. 2013;32(1):94-9. 10.1080/02763869.2013.749139.

38. Michael Castleman (1991). The Healing Herbs. Rodale Press. pp. 79-81. ISBN 978-0-87596-181-1

39. Middleton, A. (1998). History under the microscope. Nature, 393(6687), 751-752.

40. Mitsunobu R. Kano. Nanotechnology and tumor microcirculation. Advanced Drug Delivery Reviews (2013), doi: 10.1016/j.addr.2013.08.010

41. Monier-Williams, M. (1964). A Sanskrit-English dictionary: etymologically and philologically arranged with special reference to cognate Indo-European languages. MotilalBanarsidassPubl..

42. Moore FD, Smith LL, Burnap TK, et al. One stage homotransplantation of the liver fol-lowing total hepatectomy in dogs. Transplant Bull 1959; 6:103.

43. Mostafa,S.(2004), "The Father of Medicine: A Historical Reconsideration", J Med Ethics 12, p. 171-176 [176]

44. Murray JE, Merrill JP, Harrison JH, et al. Prolonged survival of human-kidney homografts by immunosuppressive drug therapy. N Engl J Med 1963; 268:1315.

45. Nobel, S. (2008). Biobanks-Integration of human information to improve health. Report of the Committee for Research Infrastructures and the Scientific Council for Medicine at the Swedish Research Council.

46. Nutton, V. (1973). "The Chronology of Galen's Early Career". Classical Quarterly 23 (1): 158-171.

47. Ong, J. M., \& da Cruz, L. (2012). The bionic eye: a review. Clinical \& Experimental Ophthalmology, 40(1), 6-17.

48. Paraskevas, G. K., Raikos, A., Ioannidis, O., \& Brand-Saberi, B. (2012). Topographic anatomy of the internal laryngeal nerve: Surgical considerations. Head\&neck, 34(4), 534-540.

49. Pearce, J. M. S. (2002). A brief history of the clinical thermometer. QJM, 95(4), 251-252.

50. Peltier, L. F. (1993). Orthopedics: History and Iconography (No. 3). Jeremy Norman Company.

51. Pevsner, J. (2009). Bioinformatics and functional genomics. Wiley-Blackwell.

52. Plato (2012), Phaedrus, Internet Classics Archive: The University of Adelaide Library, retrieved November 1, 2012.

53. Raju, T. N. (1999). "The Nobel Chronicles". The Lancet.

54. Research: Readings and commentary (pp. 7-20). Baltimore (MD): Johns Hopkins University Press. 
55. Richard L. Mueller, MD, and Timothy A. Sanborn, The history of interventional cardiology: Cardiac catheterization, angioplasty, and related interventions AM HEART J 1995;129:146-72.

56. Richmond, P. A. (1954). American attitudes toward the germ theory of disease (1860-1880). Journal of the History of Medicine and Allied Sciences, 9(4), 428- 454.

57. Robert D. Simoni, Robert L. Hill and Martha Vaughan The Discovery of Insulin: the Work of Frederick Banting and Charles Best. (Best, C. H., and Scott, D. A. (1923) J. Biol. Chem. 57, 709-723)

58. Rosania K. Key to growing blood-forming stem cells discovered. Lab Anim $\quad$ (NY). 2012 Feb 17;41(3):56. doi: 10.1038/laban0312-56b.

59. Rosenblum D, Dan Peer. Omics-based nanomedicine: The future of personalized oncology. Cancer Lett. (2013), http://dx.doi.org/10.1016/j.canlet.2013.07.029.

60. Rufus, E.(1869) entry in Dictionary of Greek and Roman Biography and Mythology, page 669. Volume 3.

61. Rutkow, Ira M. (1993), Surgery: An Illustrated History, London and Southampton: Elsevier Science Health Science div, ISBN 0-8016-6078-5.

62. Schwartz R, Dameshek W. Drug-induced immunological tolerance. Nature 1959; $\quad 183: 1682$.

63. Semba, R. D. (2012). The Discovery of the Vitamins. International Journal for Vitamin and Nutrition Research 82, 310-315

64. Singer, Charles; Underwood, E. Ashworth (1962), A Short History of Medicine, New York and Oxford: Oxford University Press, Library of Congress ID: 62-21080.

65. Siraisi, Nancy G., (1991) GirolamoCardano and the Art of Medical Narrative, Journal of the History of Ideas. pp. $587-88$.

66. Snellen, Herman Adrianus (1995), Willem Einthoven (18601927) Father of Electrocardiography, Life and Work, Ancestors and Contemporaries, Dordrecht: Kluwer Academic Publishers, ISBN 0-7923-3274-1

67. Sobkowiak, W. (2009). John C. Wells. Longman Pronunciation Dictionary. International Journal of Lexicography, 22(2), 191-209.

68. Starzl TE, Groth CG, Brenschneider L, et al. Orthotopic transplantation of the human liver. Ann Surg 1968; 168:392.

69. Starzl TE, Marchioro TL, Von Kaulla KN, Hermann G, Brittain RS, Waddell WR: Homotransplantation of the liver in humans. SurgGynecolObstet 117:659- 676, 1963.

70. Steinbrook, R. (2006). The potential of human papillomavirus vaccines. New England Journal of Medicine, 354(11), 1109-1112.

71. Storry, J. R., \& Olsson, M. L. (2009). The ABO blood group system revisited: a review and update. Immunohematology, 25(2), 48-59

72. Sujit K. Bhutia, Swadesh K. Das, BelalAzab, Mitchell E. Menezes, Paul Dent, Xiang- Yang Wang, DevanandSarkar, Paul B. Fisher. Targeting breast cancer initiating/stem cells with melanoma differentiation associated gene-7/interleukin-24 (mda-7/IL-International Journal of Cancer, 2013; DOI: $\quad$ 10.1002/ijc.28289.

73. Sullivan, R. (1996).The identity and work of the ancient Egyptian surgeon.Journal of the Royal Society of Medicine, 89(8), 467.
74. Takanori T, Keisuke Sekine, Masahiro Enomura, Hiroyuki Koike, Masaki Kimura, TakunoriOgaeri. Vascularized and functional human liver from an iPSC-derived organ bud transplant. 25 July $2013 \mathrm{Vol} 499$ Nature.

75. Tosaya, C. A., \&Sliwa, J. W. (2003). U.S. Patent Application $10 / 612,171$.

76. Vanantwerp, W. P., Walsh, A. J., Manda, V. R., \&Burnes, J. (2012). U.S. Patent No. 20,120,277,155. Washington, DC: U.S. Patent and Trademark Office.

77. Von Hippel A (1888) EineneueMethode der Hornhaut transplantation. Graefes Arch Ophthal 34,108-130.

78. Wakounig, M. (2012). From Collective Memories to Intercultural Exchanges. LIT VerlagMünster

79. Walters, J. (1998). Making a Spectacle: Deviant Men, Invective, and Pleasure.Arethusa, 31(3), 355-367.

80. Wei He, Dongmin Wang, Zhangqun Ye, WeihongQian, Yan Tao, Xiaofeng Shi, Ling Liu, Jin Chen, Ling Qiu et al. Application of a nanotechnology antimicrobial spray to prevent lower urinary tract infection: a multicenter urology trial. Journal of Translational Medicine 2012, 10(Suppl 1):S14.

81. Wellmann, M. (1888). Zur Geschichte der MedicinimAlterthume. Hermes,23(4), 556-566.

82. Widmer AF (2008). "Ceftobiprole: a new option for treatment of skin and soft- tissue infections due to methicillin-resistant Staphylococcus aureus". Clin. Infect. Dis. 46 (5): 656-658.

83. Wilson RE, Dealy JB, Sadowsky N, et al. Transplantation of homologous bone mar-row and skin from common multiple donors following total body irradiation. Surgery 1959; 46:261.

84. Withington, E.T. (1894)"Medical history from the earliest times: A popular history of the art of healing,", London, The Scientific Press, pages 14-23 (Chapter IV: Medicine in Ancient Egypt)

85. WMA Press Release (2000) WMA revises the Declaration of Helsinki.

86. Zirm E (1906) EineerfolgreichetotaleKeratoplastik. ArchivOphthalmol 64, 580-593.

87. Zukoski C, Lee HM, Hume DM. The prolon-gation of functional survival of canine renal homografts by 6mercaptopurine. Surg Forum 1960; 11:470.

88. Zumla, A., \&Lulat, A. (1989). Honey--a remedy rediscovered. Journal of the Royal Society of Medicine, 82(7), 384. 